\title{
A METHODICAL APPROACH TO SUPPORT CONCEPTUAL DESIGN FOR MULTI-MATERIAL ADDITIVE MANUFACTURING
}

\author{
Watschke, Hagen; Kuschmitz, Sebastian; Heubach, Julius; Lehne, Guido; Vietor, Thomas \\ Technische Universität Braunschweig, Institute for Engineering Design
}

\begin{abstract}
Additive manufacturing (AM) opens new possibilities for innovative product designs. However, due to a lack of knowledge and restrained creativity because of design fixations, design engineers do not take advantage of AM's design freedom. Especially multi-material AM provides new opportunities for functional integration that hardly considered in ideation. To overcome barriers in the development of solution ideas and utilizing such new design potentials, new design methods and tools are needed. Therefore, in this contribution, a methodological approach for a function-oriented provision of solution principles specific to material extrusion is presented. A tool is developed to facilitate effective guidance in developing solution ideas and to foster a realistic concretization by providing a combination of opportunistic and restrictive AM knowledge. Besides general levers of AM, process-specific design opportunities support the design engineers in exploiting AM's potentials, especially those who are not familiar with Design for AM. Finally, the applicability of the methodological approach is evaluated in an academic study by means of redesigning a hand prosthesis with a grab function.
\end{abstract}

Keywords: Design for Additive Manufacturing (DfAM), Additive Manufacturing, Conceptual design, Design methods

\section{Contact:}

Watschke, Hagen

Technische Universität Braunschweig

Institute for Engineering Design

Germany

h.watschke@tu-braunschweig.de

Cite this article: Watschke, H., Kuschmitz, S., Heubach, J., Lehne, G., Vietor, T. (2019) 'A Methodical Approach to Support Conceptual Design for Multi-Material Additive Manufacturing', in Proceedings of the 22nd International Conference on Engineering Design (ICED19), Delft, The Netherlands, 5-8 August 2019. DOI:10.1017/dsi.2019.70 


\section{INTRODUCTION}

Additive manufacturing (AM) has been established for the direct manufacturing of functional parts (33.1\%) in comparison to its original purpose for prototyping (31.1\%) (Weiss et al., 2018, Wohlers Associates, 2018). Due to its unique design capabilities AM enables an innovative product design that requires a change of working principles and challenges designer's creativity in conceptual design (Kumke et al., 2017, Yang et al., 2018, Richter et al., 2018). Besides, designers are not familiar with this new design freedom and often take it into consideration too late in the product development process or utilize AM's design potential only selectively (Richter et al., 2018, Pradel et al., 2018). Multi-material AM provides new opportunities in functional integration in particular, whereas material extrusion (ME) offers a vast potential regarding the combination of different materials into one part (Vaezi et al., 2013). For example, ME allows the integration of damping structures (Rothe et al., 2018), tactile sensors (Leigh et al., 2012) or radiant heat surfaces (Watschke et al., 2019). On the basis of a survey Weiss et al. (2018) revealed that function integration is one of the main reason for interest in design for AM. To take advantage of such new design capabilities in ideation a provision of AM specific knowledge is needed at the right time during the early design stages and with the right content (Laverne et al., 2017). In the field of Design for additive manufacturing (DfAM) the provision of knowledge can be divided into two different categories: opportunistic and restrictive DfAM (Laverne et al., 2015). The latter category aims at the limitations of AM to ensure manufacturability, while opportunistic DfAM focuses at design possibilities to support its utilization in product design. However, the design possibilities of multi-material AM are hardly considered in both DfAM approaches. There only exist rudimentary frameworks (Yao et al., 2018) or very general design heuristics (Blösch-Paidosh and Shea, 2017, 2018).

The main objective of this paper is the development of a tool for a systematic provision of knowledge regarding multi-material AM specific to ME to support the consideration of respective design potential in ideation. Therefore, based on an analysis of additively manufactured multi-material parts and properties of available materials solution principles are derived. Further, to attain a better understanding of these principles opportunistic and restrictive AM knowledge is supplemented referring to literature. Finally, the application of the developed tool is demonstrated by an academic study through redesigning a hand prosthesis to show both, the guidance during ideation by selection of pertinent solution principles and the concretisation of solution ideas by considering AM's potentials and limitations.

\section{LITERATURE REVIEW}

This section gives an overview of both general and AM specific approaches for provision of knowledge in conceptual design. Moreover, selective opportunistic DfAM methods and tools are presented.

\subsection{Provision of general and AM specific knowledge in conceptual design}

To overcome design fixation and to expand the design solution space an abstraction of the design problem is needed (Yang et al., 2018, Richter et al., 2018). Yang et al. (2018) add that a radical innovation in product design requires a change of working principles by both, a function-oriented access and provision of novel design principles specific to AM. Several product models have been established, for instance, function models or product structure models; each represents only part of the available information about the current design state in order to support a specific task. Besides the abstraction and designer's creativity the provision of appropriate knowledge is a key factor for ideation and decision making in conceptual design based on design process guidance (Fu et al., 2016, Pradel et al., 2018, Richter et al., 2018). To support ideation solution principles describe the realisation of one or more linked functions by selection of effects or working principles (Verein Deutscher Ingenieure e.V., 2018). In general, solution principles can be formulated in a general way for an broad application (e.g. TRIZ) and design heuristics (Yilmaz and Seifert, 2010) or in a more specific way, e.g. related to operations, objects or solutions, and provided in form of design catalogues (Roth, 2001). Furthermore, Ziebart (2012) presents a collection of principles specific to function integration to achieve design goals, for instance, reducing of assembly time and costs or increasing part performance.

In the field of DfAM many approaches have been developed for supporting the provision of AM specific knowledge in conceptual design and ideation, in particular. Watschke et al. (2017) adapt general ideation 
methods to the characteristics of AM by incorporating specific opportunistic and restrictive knowledge. Kumke et al. (2017) present a systematisation of AM specific value propositions that are linked to design goals to help design engineers considering AM's design freedom. General design heuristics for AM derived from existing AM artefacts are proposed by Blösch-Paidosh and Shea $(2017,2018)$ to support ideation. Bin Maidin et al. (2012) identify and categorise several AM specific design features to facilitate conceptual design and encourage inspiration. To consider AM's design potentials regarding functional integration and parts consolidation Becker et al. (2005), Yang and Zhao (2015), and Yang and Zhao (2016) present procedures and postulate design principles. Based on function-oriented design catalogues Weiss et al. (2016) provide a collection of AM-compliant solutions in comparison to conventional design that are classified by general functions. Similarly, Kamps et al. (2017) developed an approach for a systematic biomimetic design utilizing biomimetic analogies in design evolution. Yang et al. (2018) derived AM design potentials from literature and subsumed them into specifics cards including a short description, principle specific benefits, and applicability. In addition, they propose a function-behaviourstructure for a systematic access to novel working principles.

\subsection{Tools for provision of AM knowledge}

Yang et al. (2018) emphasise the challenge in provision of AM knowledge for ideation to understand the great number of information and select only the most pertinent solutions regarding design requirements, especially for novice designers in the field of DfAM. A further challenge is to link specific design rules to related design potentials in order to evaluate and ensure manufacturability (Pradel et al., 2018). For this reason, in literature several systems exist for supporting conceptual design and evaluation, embodiment and detailing of design as well as process selection in AM (Kumke et al., 2016). Following, tools for provision AM knowledge in ideation are presented.

Bin Maidin et al. (2012) proposed a requirement-oriented interactive DfAM design feature database to inspire designers by AM specific design features and facilitate the development of suitable solution ideas. Similarly, Laverne et al. (2017) introduce an interactive support tool to provide tailored AM knowledge depending on design tasks in early design stages. The creation of innovative solutions is encouraged by knowledge about design features and possibilities. In contrast to that, Kumke et al . (2017) developed a more generic approach for the provision of AM specific design potentials. Based on a comparison of AM with conventional manufacturing processes and an analysis of AM's inherent properties they identified 22 levers to realise different value propositions. The selection of AM design potentials regarding specific design goals is supported by means of an interactive graph. Moreover, Kamps et al. (2017) developed a TRIZ-based design framework, that includes a database of biomimetic analogies to support the evolution of design solutions regarding AM based on a functional analysis. Weiss et al. (2018) created an internet-based platform to facilitate the development of additively manufactured parts. The contents of the tool is structured by the stages of the general design development process of VDI Guideline 2221. Besides general information, for instance, about AM processes and design rules, searching for solution principles is supported by a function-oriented access to AM specific solution ideas.

\subsection{Limitations of previous research}

From the review of prior research, two main limitations can be identified regarding the preparation and provision of solution principles for multi-material AM specific to ME. First, the design potential of multi-material AM is if at all, only considered rudimentarily in the proposed design heuristics and principles (see subsection 2.1). Further, there is a lack of information concerning process-related benefits or limitations to evaluate the suitability of design principles in more detail. Therefore, a systematic consideration in ideation for a change of working principles is not possible for designers, especially for all those who are not familiar with DfAM. Second, multi-material AM requires a particular guidance in both identification of pertinent solution principles and arrangement of product architecture since process limitation in regards to compatibility of different materials hast to be considered as a key factor, in particular (Watschke et al., 2018).

In this contribution, a new approach for the preparation of solution principles for multi-material AM for ME is presented. The provided principle cards include a description of the working principle and a linkage to process-related AM knowledge to influence specifically the resultant part properties. To 
ensure an effective guidance of designers in conceptual design and arrangement of product architecture, an interactive tool is proposed with its main functionalities.

\section{DERIVATION OF SOLUTION PRINCIPLES FOR MULTI-MATERIAL AM}

In general, in the early design stages the provision of opportunistic knowledge ('Design with X') about AM capabilities is much more effective than knowledge about specific process limitations (Laverne et al. 2016). However, for both an evaluation of pertinent solutions for the design problem and the arrangement of the product architecture manufacturability ('Design for X') has also been considered in conceptual design (Laverne et al., 2017, Pradel et al., 2018, Weiss et al., 2018). In addition, Pradel et $a l$. (2018) criticise the lack of effective guidance in conceptual design. They argue that process-related factors need to be taken into account since these capabilities can be utilized advantageously in design synthesis. Even more, Yang et al. (2018) underline the importance of an extraction of functional information and novel working principles from existing AM case studies to stimulate radical innovation and support a change of working principles in redesign. Therefore, in this section novel solution principles specific to multi-material AM with material extrusion are derived from both AM case studies and material properties. Based on this, principle cards are presented to provide principlerelated knowledge and facilitate their application and selection in ideation.

Fu et al. (2016) categorise design principles in principles, guidelines and heuristics. Based on a literature review they propose formal definitions for the three terms. A principle is postulated as "A fundamental rule or law, derived inductively from extensive experience and/or empirical evidence, which provides design process guidance to increase the chance of reaching a successful solution." (Fu et al., 2016). Whereas a guideline "[...] provides design process direction to increase the chance of reaching a successful solution." (Fu et al., 2016) and a heuristic "[...] provides design process direction to increase the chance of reaching a satisfactory but not necessarily optimal solution." (Fu et al., 2016).

This contribution aims at the identification of principles and the provision of specific knowledge regarding multi-material $\mathrm{ME}$, to facilitate finding solution ideas and their concretisation. To find design principles, among other things, an analysis of existing designs, e.g. in literature, consumer products or patents, and utilising experience of engineers or designers are promising strategies ( $\mathrm{Fu}$ et al., 2016). Blösch-Paidosh and Shea $(2017,2018)$ successfully adapted an approach developed by Yilmaz and Seifert (2010) to find design heuristics specific to AM by analysing key functions of 275 existing AM artefacts. However, regarding multi-material AM only three heuristics could be identified. They postulate the utilisation of multiple materials to achieve functionality and variable material properties as well embedding functional material. The formulations of these heuristics are very general, thus an application in conceptual design is difficult without specific additional knowledge regarding multi-material AM as well as available materials and their specific properties. In a similar way, Kumke et al. (2017) mentioned AM's potential regarding multi-material design in order to combine "different materials in one part" and to realise "continuous material transitions".

Therefore, more specific solution principles for multi-material AM, especially for ME, has been derived from both, AM artefacts and properties of available materials. In total, 41 solution principles are identified. Based on a literature review, the identified principles are complemented by relevant additional opportunistic and restrictive AM knowledge to improve their application in conceptual design stage related to Richter et al. (2018). Figure 1 and Figure 2 exemplarily shows the preparation of knowledge in form of principle cards using the example for the integration of damping structures (P02). The front and back show the provided knowledge about a particular design principle and are applied successfully in ideation workshops in academic and industrial studies. Besides a short description of the solution principle on the front, a detailed explanation of the working principle and a visualisation are added to foster both, a deep understanding and easy application of the principle in comparison to the design heuristics provided by Blösch-Paidosh and Shea $(2017,2018)$ and the specifics cards proposed by Yang et al. (2018). Further, to assess suitability for a particular design problem affected goals in context of the product development process are illustrated with positive and negative influences. On the backside AM capabilities related to the solution principle are presented to support a concretisation of solution ideas by utilising AM design potentials (see Figure 2). For instance, in case of the integration of damping structures the dependency of the anisotropy of mechanical properties on process parameters is shown, e.g. raster angle orientation. In order to provide a realistic assessment of the applicability of the principles basic information about process and 
material related limitations are also represented in form of advises that are less specific and more qualitative than AM design rules. In consequence, a selection of pertinent solution principle is facilitated (Laverne et al., 2017).

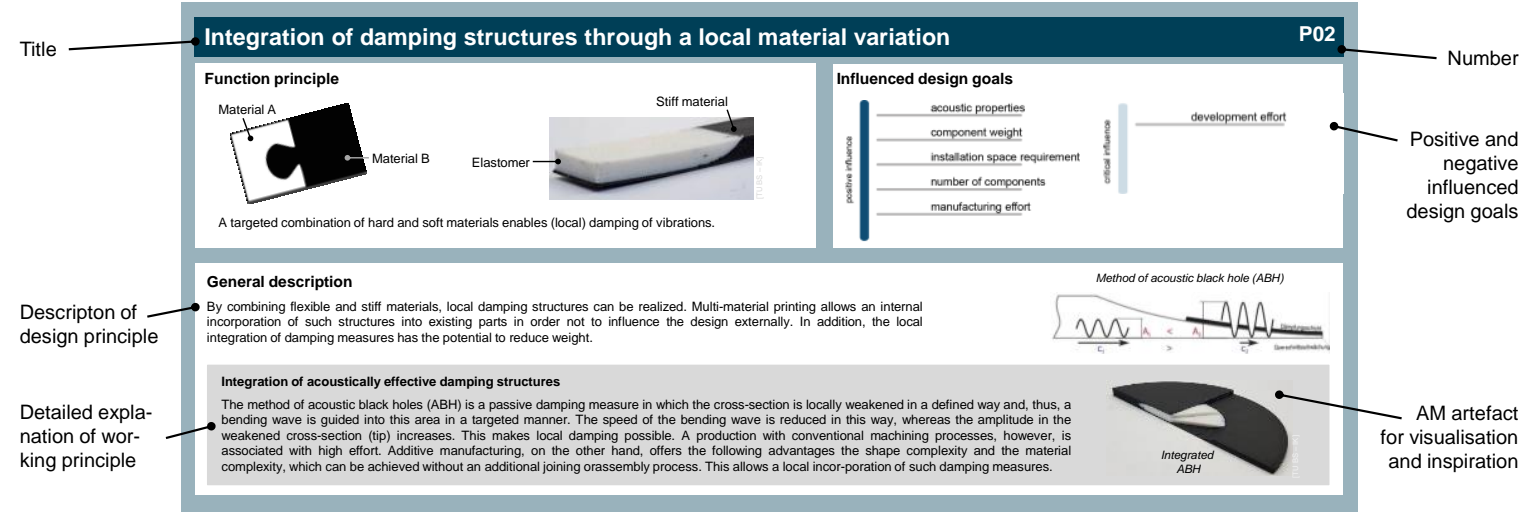

Figure 1: Front of principle card for the integration of damping structures

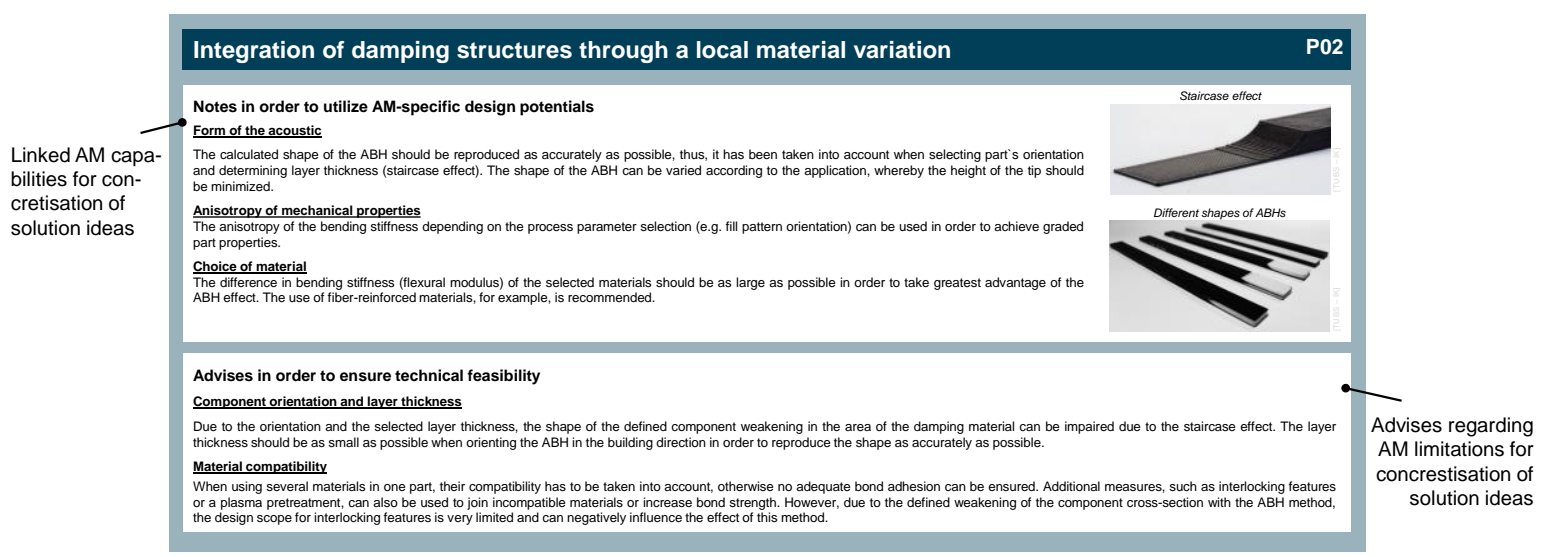

Figure 2: Back of principle card for the integration of damping structures

\section{TOOL FOR SUPPORTING CONCEPTUAL DESIGN SPECIFIC TO MULTI- MATERIAL AM}

In this section, the developed tool for supporting conceptual design by considering AM's capabilities regarding multi-material design is presented. First, the requirements are formulated based on literature. Second, the framework of the tool with its key functions and content is shown.

\subsection{Requirements on a supporting tool for multi-material AM for ideation}

Weiss et al. (2018) conducted a survey of 35 persons in the field of DfAM and derived requirements concerning content and functions of a tool for supporting product development, in particular, for AM. The most important information that should be included are "restrictions for particular AM technologies", "examples of solution principles", "approach for the development of additively manufactured parts", and "assessment of the potential of using AM technologies for a product or product idea". Further, this information has to be "searchable", "filterable", and "enhanceable" and preferably provided in an "internet-based" system.

In ideation and providing AM knowledge Richter et al. (2018) point out the importance of an abstract problem definition with product models to overcome designers' restrained creativity caused by design fixations and get access to solution principles. In addition, Yang and Zhao (2016) and Yang et al. (2018) add the relevance of a function-oriented access to design principles to force innovative design solutions with AM by changing working principles, especially for function integration. Besides these, an embedding of AM knowledge and DfAM tools in the product development process is essential for a consideration of the new design freedom of AM (Laverne et al., 2017, Kumke et al., 2016). In addition, Kumke et al. (2017) and Richter et al. (2018) emphasise the lack of knowledge about capabilities and limitations that requires a specific knowledge provision related to early design stages 
(Laverne et al., 2017). Vaezi et al. (2013) underline the material compatibility as a key factor for realising multi-material AM. Therefore, the interface strength has to be considered in selection of materials that are linked to a specific property and principle.

Consequently, the following requirements on the tool are postulated:

- Embedded in the product development process to enable a reconsideration of product architecture to exploit AM's design potentials and to facilitate the access to the solution principles by function orientation

- Effective guidance of designers to avoid information overflow during selection of pertinent solution principles and development of solution ideas

- Specific knowledge provision regarding both, opportunistic and restrictive AM knowledge, for a realistic concretisation of generated solution ideas by considering AM's capabilities and limitations

- AM capabilities: process related levers specific to solution principle, for instance, to influence stiffness or electrical conductivity by raster angle orientation

- AM limitations: process related restrictions specific to solution principle, e.g. surface roughness or post-processing depending on build orientation

- Considering material compatibility for evaluating general technical feasibility of the solution principles specific to design problem and supporting embodiment design

\subsection{Content and functions of the tool}

At the time that this paper was written, some functionalities, for instance, filters and automatic sort algorithm are still under development are not finally implemented. However, these functions are also displayed in the figures below to demonstrate their operating principles. In the following particular content and functions of the tool are presented.

First, to ensure effective guidance of designers an interactive database system is developed that allows a filtering of the provided information. In order to facilitate access to the tool based on product models the identified principles (see section 3) are assigned to general functions in regard to definitions of Roth (2000) and Stone and Wood (1999). Due to that systematisation, a goal-oriented access through an abstract problem definition is facilitated, for instance, on the basis of a function structure or a product architecture with functions linked to components. Figure 3 shows the interactive function matrix. By moving the mouse over a principle number, its title is displayed to provide information regarding a first evaluation of the pertinence of the solution principle for the design problem. Detailed information about working principle and affected design goals (c.f. Figure 1) are presented by clicking on principle numbers. Hence, the user is able to assess suitability more precisely by gaining a deep understanding about the working principle and its benefits.

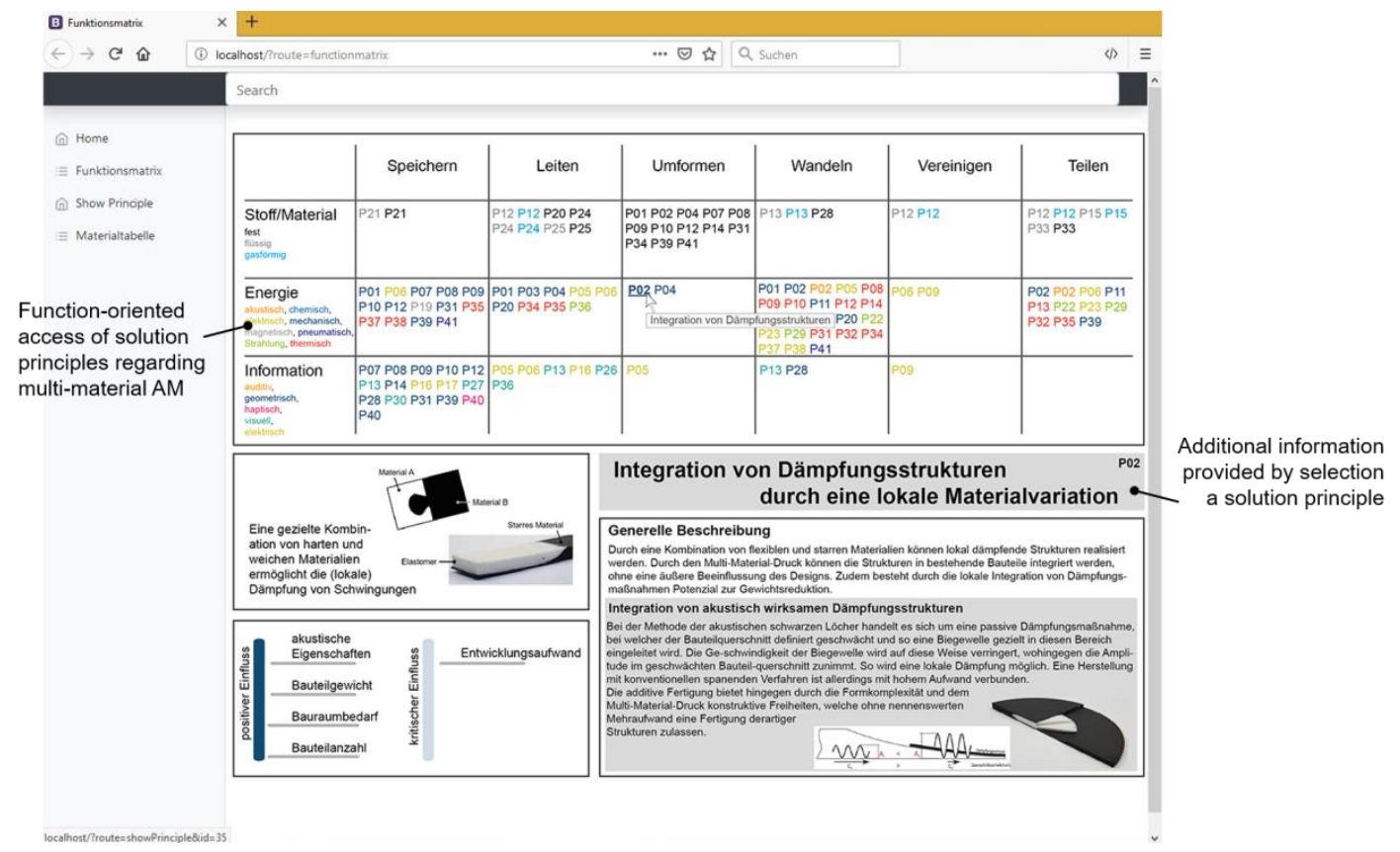

Figure 3: Systematisation of solution principles for a function-oriented access 
Special to solutions principles regarding multi-material AM is a linkage to different material properties and materials, respectively. Figure 4 represents this linkage between principles, properties, and materials. If a user selects a pertinent solution principle (see Figure 3), the connected material properties and appropriate materials are displayed. The compatibility of the materials is shown in a matrix, to facilitate the selection and assessment of suitable material combinations. The materials in the first row belongs to material property one and the materials in the first column to material property two, respectively. The listed materials are in each case automatically assorted downward by the particular property related to the selected design principle. In the case of incorporated passive damping structures by the method of acoustic black holes the difference in flexural rigidity determines the impact, thus the flexible materials are sorted in descending order according to minimum flexural modulus, whereas the rigid materials are sorted according to maximum flexural modulus in descending order. By means of a filter function, the material selection can further be limited to specific requirements of the design problem, for instance, related to additional restrictions like heat resistance or chemical resistance.

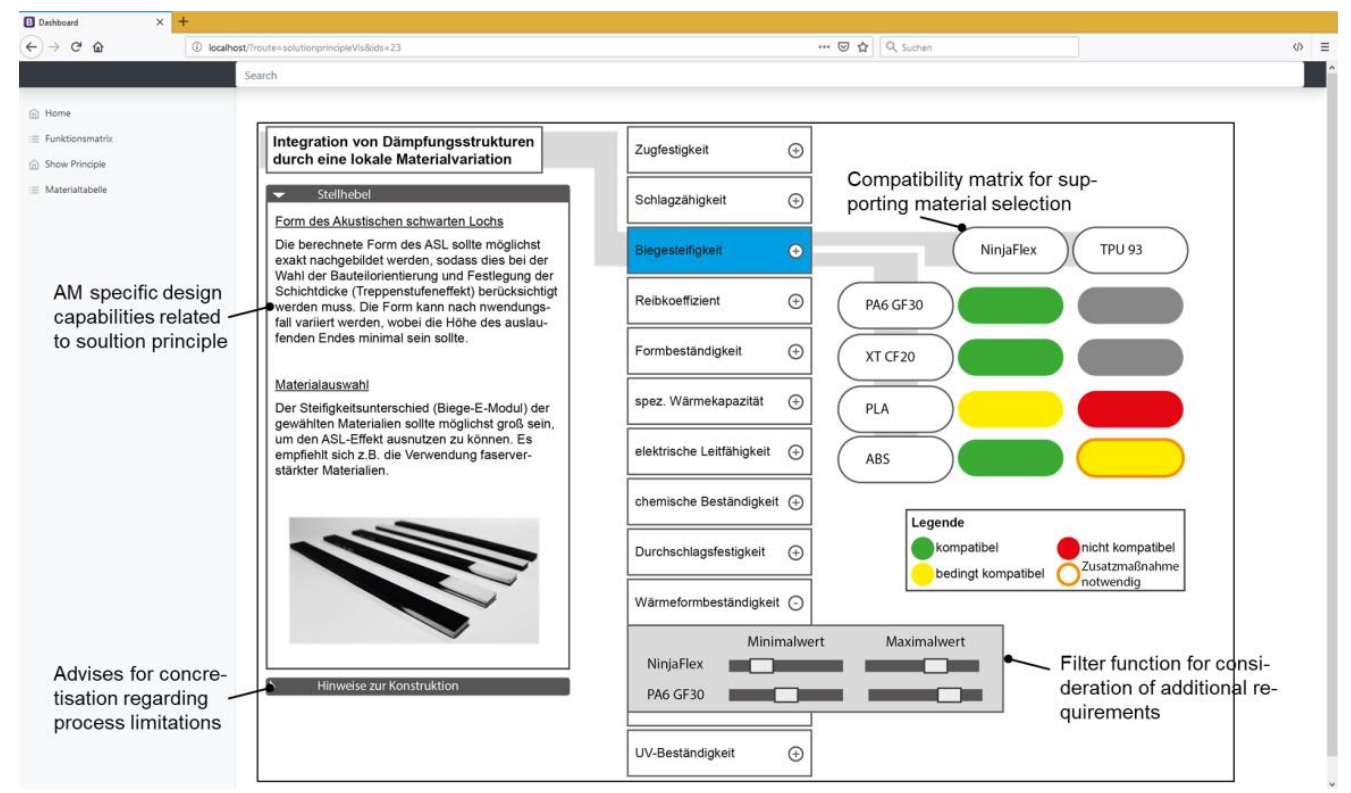

Figure 4: Linkage of both, selected principle with properties and appropriate materials with their compatibility; solution principle related process specific levers and limitations

In addition, detailed information about material properties, AM specific influencing factors on these properties and material compatibility are deposited and can be displayed by selecting the respective button. As a result, both tasks are supported, the concretisation of solution ideas by providing knowledge about AM's process specific capabilities and ensuring technical feasibility due to prepared knowledge about basic limitations and material compatibility as a key factor in multi-material AM.

\section{APPLICATION OF THE INTERACTIVE TOOL IN AN ACADEMIC STUDY}

This section intend to demonstrate an application of the developed tool in design education. For this reason, a study in an academic setting was conducted at the Institute for Engineering Design at the Technische Universität Braunschweig. Four students with little to advanced knowledge in DfAM from mechanical engineering background participated in the workshop that lasted 8 hours. The workshop was divided into three phases: reassessment of design problem by abstraction, identification of pertinent solution principles for redesign and concretisation of selected solution ideas in CAD by considering AM specific design freedom and restrictions. Subsequent to the workshop, the manufacturability of selected solution ideas was tested by prototyping. The goal of this workshop was the redesign of a hand prosthesis with grab function by a goal-oriented utilisation of multi-material AM's design potentials. Figure 5 represents the procedure of the workshop with single steps from reassessment of the problem over ideation and concretisation of solution ideas to demonstration of technical feasibility by prototyping of selected structures. 
In the first step, the participants of the workshop prepared a function structure for identifying relevant functions that have been realised. Based on this product abstraction, the participants were able to identify pertinent solution principles by means of the interactive tool, due to the guided access and the provided additional information about the working principles. Amongst others, the following solution principles were shortlisted:

- P01: Integration of hinges by local usage of flexible materials

- P02: Integration of damping structures by usage of flexible materials

- P10: Integration of a grab function by usage of material deformation of shape memory polymers

- P11: Locally increased friction due to usage of multiple materials

- P16: Integration of sensor functions in bending structures by usage of conductive materials

- P20: Integration of slide bearings by usage of multiple materials

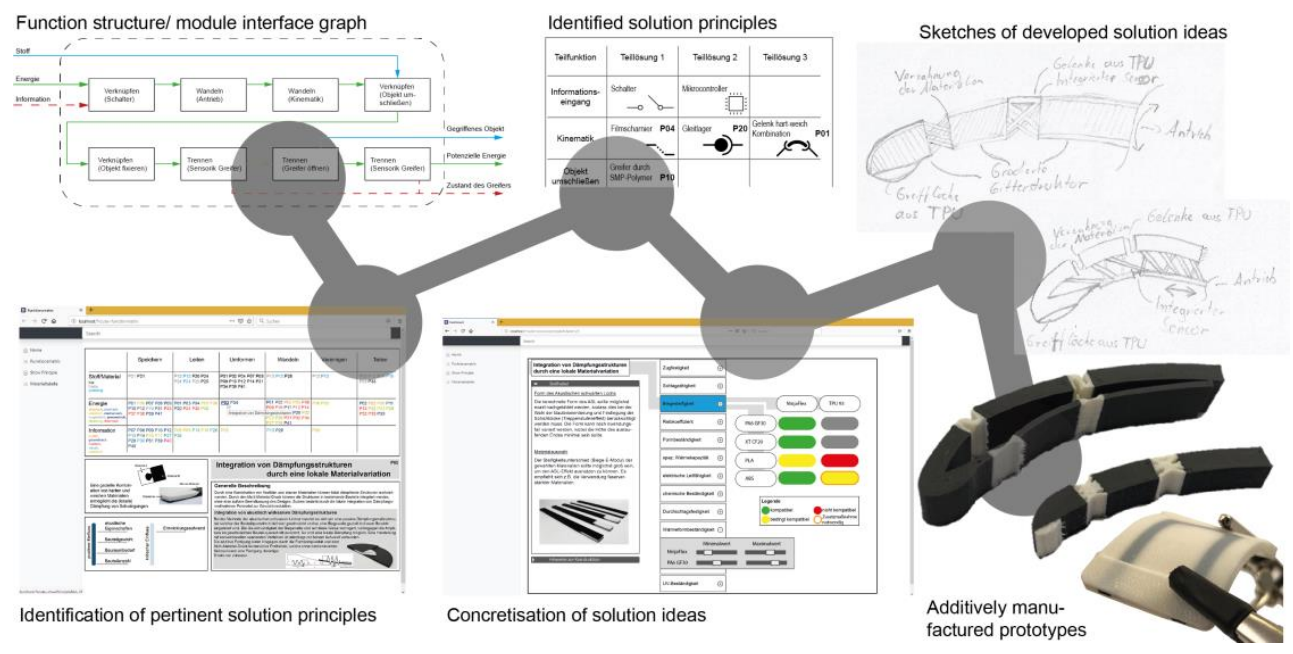

Figure 5: Procedure of the workshop from problem reassessment over ideation and concretisation of solution ideas to prototyping

The different solution principles were structured in a morphological box respective to the realisable functions. In the further step, individual solution principles were selected for a concretisation. Subsequently, the participants assess suitability for the design task by analysing principle related design opportunities and restrictions based on the provided AM knowledge in the tool. Hence, sketches for different solution ideas were realised by utilising general levers of AM, for instance, hierarchical structures for varying hinge's stiffness and raster angle orientation for adjusting electrical resistivity for the integrated sensor. Based on this, simplified CAD models were developed to check technical feasibility of the generated solution ideas. Finally, the selection of appropriate materials for the prototypes was supported by using both functionalities of the tool, the filter function for considering additional requirements and the compatibility matrix. The manufacturing process including slicing was not part of the workshop.

In summary, the results of the workshop show innovative solution ideas for redesigning a hand prosthetic by taking design freedom of multi-material AM into account. In Figure 5 the developed concepts represented as sketches and the additively manufactured prototypes are shown. The hinges are realised by using a flexible material as a hinge. Further, in one solution the flexible material is also used for increasing friction in the fingertip and, therefore, improving the grab function. The principle of the embedding of a conductive structure for measuring bending force in a hinge is represented as a separated part. Consequently, both the function principle and the technical feasibility of the developed solution ideas could be demonstrated. Moreover, an effective guidance in conceptual design with regard to both, AM design potentials and limitations, is possible with the tool and the provided AM knowledge. Consequently, more realistic solution ideas with respect to technical feasibility were developed, whereby still novel solution ideas were generated. Furthermore, the product abstraction fosters creativity and facilitates a function-oriented access for avoiding design fixations. However, it must be criticised that only four participants took part in this academic study. Consequently, the results can hardly be generalised. 


\section{CONCLUSION AND FUTURE RESEARCH}

Based on a literature review a methodological approach for supporting conceptual design by utilising AM's design potentials specific to multi-material ME was developed. Besides opportunistic AM knowledge, knowledge about general limitations of AM is also provided to take also technical feasibility into account, for example, material compatibility. In total, 41 solution principles specific to multimaterial AM have been derived by both, AM artefacts and material properties. To ensure an effective guidance during the single steps of conceptual design and to avoid information overflow, an interactive tool has been proposed and applied in an academic study with only four participants. The results indicate that the tool and the provided knowledge have facilitated the development of both, innovative and technical feasible solution ideas. The function-oriented access to the solution principle supports a change of working principles in comparison to the origin design. However, due to the scope of the application of the tool its validity is limited.

Therefore, in future research the applicability of the tool has to be evaluated in more studies in academic and industrial environment with participants of different expertise in the field of DfAM. Individual functionalities of the tool e.g. filter functions and sorting algorithms have to be improved and fully implemented, respectively. Furthermore, the included AM knowledge has to be expanded, for instance, regarding quantity of solution principles, guidelines for concretisation of solution ideas, and material compatibility. Besides the solution principles specific to multi-material AM, general design potentials specific to AM can also be implemented.

\section{REFERENCES}

Becker, R., Grzesiak, A. and Henning, A. (2005), "Rethink assembly design”, Assembly Automation, Vol. 25 No. 4, pp. 262-266. http://dx.doi.org/10.1108/01445150510626370.

Bin Maidin, S., Campbell, I. and Pei, E. (2012), "Development of a design feature database to support design for additive manufacturing”, Assembly Automation, Vol. 32 No. 3, pp. 235-244. http://dx.doi.org/10.1108/01445151211244375.

Blösch-Paidosh, A. and Shea, K. (2017), "Design Heuristics for Additive Manufacturing”, DS 87-5 Proceedings of the 21st International Conference on Engineering Design (ICED 17): Vol. 5: Design for X, Design to X, Vancouver, Canada, 21-25 August 2017, The Design Society, Glasgow, pp. 91-100.

Blösch-Paidosh, A. and Shea, K. (2018), "Design Heuristics for Additive Manufacturing Validated Through a User Study”, Journal of Mechanical Design, MD-17-1838. http://dx.doi.org/10.1115/1.4041051.

Fu, K.K., Yang, M.C. and Wood, K.L. (2016), "Design Principles: Literature Review, Analysis, and Future Directions", Journal of Mechanical Design, Vol. 138 No. 10, p. 101103. http://dx.doi.org/10.1115/1.4034105.

Kamps, T., Gralow, M., Schlick, G. and Reinhart, G. (2017), "Systematic Biomimetic Part Design for Additive Manufacturing”, Procedia CIRP, Vol. 65, pp. 259-266. http://dx.doi.org/10.1016/j.procir.2017.04.054.

Kumke, M., Watschke, H., Hartogh, P., Bavendiek, A.-K. and Vietor, T. (2017), "Methods and tools for identifying and leveraging additive manufacturing design potentials", International Journal on Interactive Design and Manufacturing (IJIDeM), Vol. 12 No. 2, pp. 481-493. http://dx.doi.org/10.1007/s12008-0170399-7.

Kumke, M., Watschke, H. and Vietor, T. (2016), “A new methodological framework for design for additive manufacturing”, Virtual and Physical Prototyping, Vol. 11 No. 1, pp. 3-19. http://dx.doi.org/10.1080/17452759.2016.1139377.

Laverne, F., Segonds, F., Anwer, N. and Le Coq, M. (2015), “Assembly Based Methods to Support Product Innovation in Design for Additive Manufacturing: An Exploratory Case Study", Journal of Mechanical Design, Vol. 137 No. 12, 121701-1-8. http://dx.doi.org/10.1115/1.4031589.

Laverne, F., Segonds, F., D’Antonio, G. and Le Coq, M. (2017), "Enriching design with X through tailored additive manufacturing knowledge: a methodological proposal", International Journal on Interactive Design and Manufacturing (IJIDeM), Vol. 11 No. 2, pp. 279-288. http://dx.doi.org/10.1007/s12008-0160314-7.

Leigh, S.J., Bradley, R.J., Purssell, C.P., Billson, D.R. and Hutchins, D.A. (2012), “A simple, low-cost conductive composite material for 3D printing of electronic sensors”, PloS one, Vol. 7 No. 11, p. e49365. http://dx.doi.org/10.1371/journal.pone.0049365.

Pradel, P., Zhu, Z., Bibb, R. and Moultrie, J. (2018), "Investigation of design for additive manufacturing in professional design practice”, Journal of Engineering Design, Vol. 29 No. 4-5, pp. 165-200. http://dx.doi.org/10.1080/09544828.2018.1454589. 
Richter, T., Watschke, H., Schumacher, F. and Vietor, T. (2018), "Exploitation of potentials of additive manufacturing in ideation workshops", The Fifth International Conference on Design Creativity, January 31-February 02 2018, University of Bath, UK.

Roth, K. (2000), Konstruieren mit Konstruktionskatalogen: Band 1: Konstruktionslehre, Vol. 1, 3rd ed., Springer Verlag, Berlin Heidelberg.

Roth, K. (2001), Konstruieren Mit Konstruktionskatalogen: Band 2: Konstruktionskataloge, Vol. 2, 3rd ed., Springer Verlag, Berlin Heidelberg.

Rothe, S., Blech, C., Watschke, H., Vietor, T. and Langer, S.C. (2018), "Numerical modelling of additively manufactured acoustic black holes", 47th International Congress and Exposition on Noise Control Engineering Impact of Noise Control Engineering (inter-noise 2018), 26-29 August 2018, Chicago, USA.

Stone, R.B. and Wood, K.L. (1999), "Development of a Functional Basis for Design”, Proceedings of DETC99, 1999.

Vaezi, M., Chianrabutra, S., Mellor, B. and Yang, S. (2013), "Multiple material additive manufacturing - Part 1: a review", Virtual and Physical Prototyping, Vol. 8 No. 1, pp. 19-50. http://dx.doi.org/10.1080/17452759.2013.778175.

Verein Deutscher Ingenieure e.V. (2018), Design of technical products and systems: Model of product design, Vol. 03.100.40 No. 2221 Blatt 1, Entwurf, Beuth Verlag GmbH, Berlin.

Watschke, H., Bavendiek, A.-K., Giannakos, A. and Vietor, T. (2017), “A methodical approach to support ideation for additive manufacturing in design education", DS 87-5 Proceedings of the 21 st International Conference on Engineering Design (ICED 17), 21-25 August, 2017: Vol. 5: Design for X, Design to X, Vancouver, Canada, 21-25 August 2017, The Design Society, Glasgow, pp. 41-50.

Watschke, H., Hilbig, K. and Vietor, T. (2019), "Design and Characterization of Electrically Conductive Structures Additively Manufactured by Material Extrusion”, Applied Sciences, 2019, Vol. 9 No. 4, p. 779. http://dx.doi.org/10.3390/app9040779.

Watschke, H., Waalkes, L., Schumacher, C. and Vietor, T. (2018), "Development of Novel Test Specimens for Characterization of Multi-Material Parts Manufactured by Material Extrusion”, Applied Sciences, Vol. 8 No. 8, p. 1220. http://dx.doi.org/10.3390/app8081220.

Weiss, F., Binz, H. and Roth, D. (2016), "Conception of a design catalogue for the development of functionalities with additive manufacturing", DS 85-2: Proceedings of NordDesign 2016, Volume 2, Trondheim, Norway, 10th - 12th August 2016, August 10-12 2016, Trondheim, Norway.

Weiss, F., Roth, D. and Binz, H. (2018), "Content and Functions of an Internet-Based Platform for Supporting Development of Additively Manufactured Parts”, Proceedings of 15th International Design Conference, May 21-24 2018, Dubrovnik, Croatia.

Wohlers Associates, I. (2018), "Wohlers report 2018: 3D Printing and Additive Manufacturing State of the Industry”, Annual Worldwide Progress Report, Wohlers report, 23rd, Wohlers Associates, Fort Collins, Colorado, USA.

Yang, S., Page, T. and Zhao, Y.F. (2018), "Understanding the Role of Additive Manufacturing Knowledge in Stimulating Design Innovation for Novice Designers", Proceedings of the ASME 2018 International Design Engineering Technical Conferences and Computers and Information in Engineering Conference, Quebec, Canada, August 26-29 2018, ASME, V004T05A003. http://dx.doi.org/10.1115/DETC201885644.

Yang, S. and Zhao, Y.F. (2015), “Additive manufacturing-enabled design theory and methodology: a critical review”, The International Journal of Advanced Manufacturing Technology, Vol. 80 No. 1-4, pp. 327342. http://dx.doi.org/10.1007/s00170-015-6994-5.

Yang, S. and Zhao, Y.F. (2016), "Conceptual design for assembly in the context of additive manufacturing", Solid Freeform Fabrication Symposium 2016, August 8-10 2016, University of Texas at Austin, USA.

Yao, X., Moon, S.K., Bi, G. and Wei, J. (2018), "A multi-material part design framework in additive manufacturing", The International Journal of Advanced Manufacturing Technology, Vol. 16 No. 11, p. 2369. http://dx.doi.org/10.1007/s00170-018-2025-7.

Yilmaz, S. and Seifert, C.M. (2010), "Cognitive Heuristics in Design Ideation”, Proceedings of 11th International Design Conference, May 17-20 2010, Dubrovnik, Croatia.

Ziebart, J.R. (2012), Ein konstruktionsmethodischer Ansatz zur Funktionsintegration, Zugl.: Braunschweig, Techn. Univ., Diss., 2012, Institut für Konstruktionstechnik, Technische Universität Braunschweig, Bericht, Vol. 83, 1. Aufl., Dr. Hut, München. 